\title{
İzole Labbe Ven Trombozlu Olguda Radyolojik Bulgular
}

\author{
Radiologic Findings in A case of Isolated Thrombosis of Vein of Labbe
}

\section{Șahinde Atlanoğlu}

Dumlupınar Universitesi Eğitim Araștrma Hastanesi Radyoloji Bölümü
Dr. Șahinde Atlanoğlu \begin{abstract}
Labbe veni, lateral temporal lobun kortikal venlerinden gelen kanı toplar ve transvers sinüse drene olur. Labbe veninin
izole trombozu, oldukça nadir bir durumdur. Biz, izole Labbe ven trombozlu bir olgunun radyolojik bulgularını sunuyoruz. MR görüntüleme, sağ temporalde hemorajik infarktı gösterdi. Sağda labbe veni, tromboz ile uyumlu olarak hiperintens olarak izlendi.

Anahtar Sözcükler: Tromboz, Labbe Veni, Bilgisayarlı Tomografi, Manyetik Rezonans Görüntüleme

The vein of Labbe collects blood from cortical veins of the lateral temporal lobe and empties into the transverse sinus. Isolated thrombosis of the vein of Labbe has been rarely reported. Herein we present a case of isolated thrombosis of the vein of Labbe with radiologic findings. MR imaging showed temporal hemorrhagic infarct. The right vein of Labbe was seen as hyperintense consistent with thrombosis.

Key Words: Thrombosis, Vein of Labbe, Computed Tomography, Magnetic Resonance Imaging
\end{abstract}

Serebral venöz tromboz (SVT), genel popülasyonda tahmini yıllık insidansı milyonda 2-7 olarak tahmin edilen, görece nadir bir durumdur. Doğru ve kesin tanisı, zamanında ve uygun tedavi ile hastalık seyrinin geriye döndürülebilmesinden, akut komplikasyonların ve uzun dönem sekellerinin önemli ölçüde azaltılabilmesinden dolayı esastır (1).

Serebral venöz sistem, derin venöz sistem, kortikal venöz sistem ve dural venöz sinüslerden oluşur. Leach ve ark'nın (2) SVT'li 510 hastayı değerlendirdikleri raporlarında kortikal venöz tutulum olguların yalnızca \%6'sında bildirilmiştir. Literatürde bildirilmiş izole Labbe ven trombozlu olgu sayis ise 10'dan daha azdir (2-6). Biz burada izole Labbe ven trombozu saptanan bir olgunun radyolojik bulgularını, literatür bilgileri eşliğinde sunuyoruz.

\section{Olgu Sunumu}

Otuzbeş yaşındaki kadın hasta, bir hafta önce başlayan, ağrı kesiciye yanıt vermeyen sıkıştırır tarzda baş ağrısı şikayetine, konuşmasında bozulma eklenmesi üzerine nöroloji bölümünde değerlendirildi ve muayenesinde sol hemihipoestezi, parestezi saptand. Özgeçmişinde appendektomi öyküsü mevcuttu, soygeçmişinde özellik saptanmadi. Hastanın çekilen manyetik rezonans görüntülemesinde (MRG) sağ temporal bölgede, çevresel ödem alanının içerisinde, hem T1 ağırlıklı görüntülemede (AG), hem T2AG'de ağırlıklı olarak hiperintens izlenen, difüzyon ağırlıklı görüntülemesinde $(b=1000)$, heterojenhiperintens, ADC görüntülemesinde hipointens hemorajik infarkt alanı izlendi. Sağ Labbe veni, hemorajik infarkt alanı lateral komşuluğunda T1 ve T2 AG'lerde hiperintens olarak izlenmekteydi ve trombüse bağlı "hiperintens ven işareti" olarak kabul edildi (Şekil 1). MRG bulguları sağ Labbe veninde tromboza bağlı hemorajik infarkt olarak değerlendirildi.

\section{Tartıșma}

Kortikal venler, dural sinüslere drene olurlar ve morfolojik yap1 ve lokalizasyonları değişkenlik gösterir $(1,3,4)$. Genellikle drene ettikleri kortikal alanın adıyla tanımlanırken geniş kortikal venlerden ikisi özel olarak adlandırılmıştır $(2,4)$. Bunlardan biri olan Labbe veni (diğeri Trolard veni olup bu ven santral sulkus düzeyinde süperior sagittal sinüse drene olan dominant parietal lob kortikal venidir) temporal lob lateral yüzeyinde anteroposterior yönelimle seyreder ve transvers sinüse drene olur $(2,4)$. $\mathrm{Bu}$ damar, kontrastsız MR görüntülerde temporal lobun lateral yüzeyinde akım kaybı şeklinde izlenir (4). 

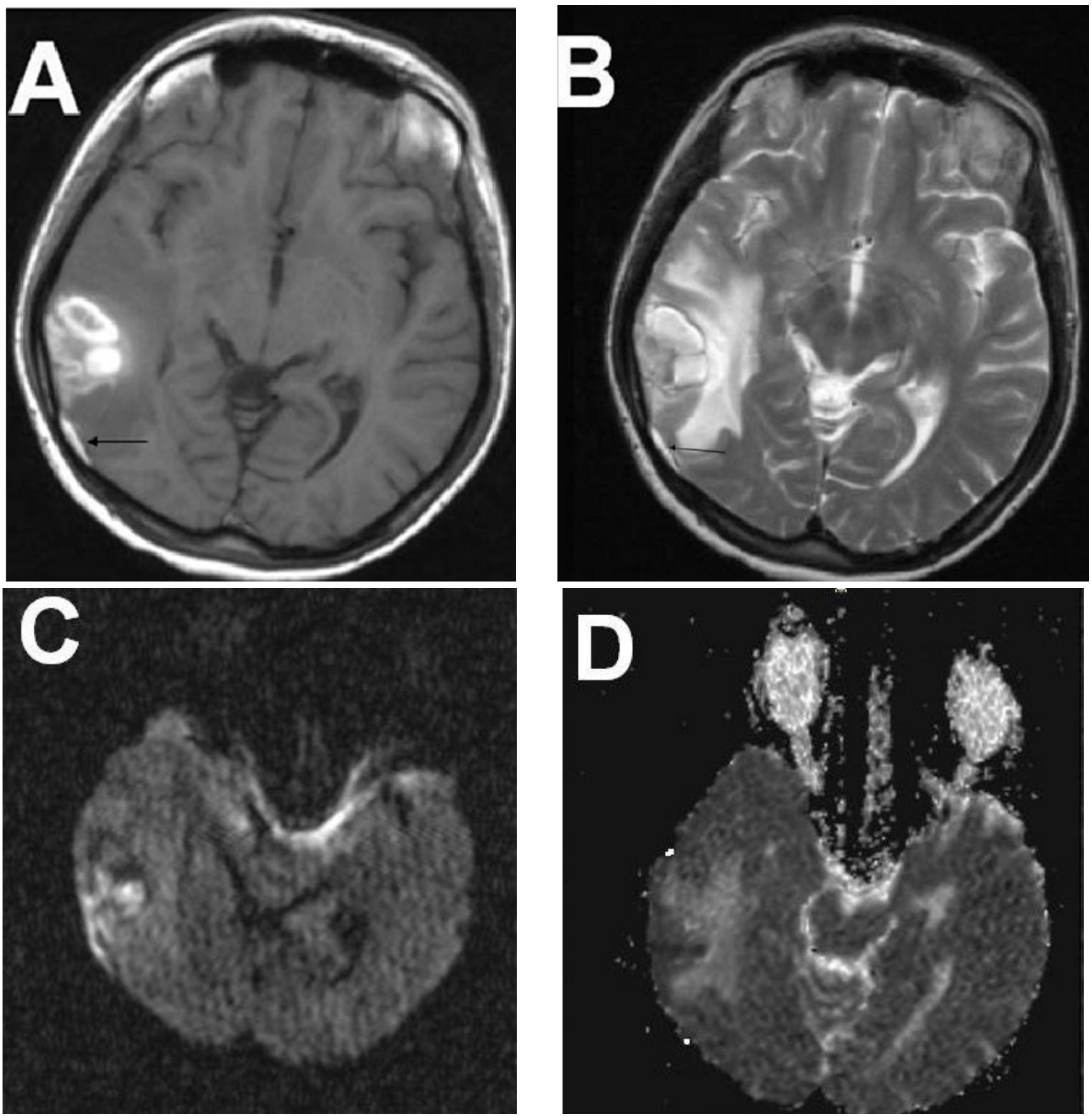

Sekil 1 :T1 AG (A) ve T2 AG'de (B) sağ temporal lob lateral kesiminde, her iki sekansta da ağırlıklı olarak hiperintens izlenen ve çevresel belirgin ödem alanının eşlik ettiği hemorajik infarkt alanı izleniyor. Hemorajik infarkt alanı posterolateral komşuluğunda hem T1AG'de, hem T2AG'de hiperintens izlenen tromboze Labbe veni görülüyor (oklar). Hemorajik infarkt alanı lokalizasyonunda sitotoksik ödemi temsil eden, difüzyon ağırlıklı görüntülemede $(b=1000)(C)$ heterojen-hiperintens ve ADC haritasında (D) hipointens sinyal değişiklikleri seçiliyor.

$\mathrm{Bu}$ venin trombozu, karakteristik olarak temporal lob lateral kesiminde fokal kortikal ödem, hemoraji veya hemorajik infarkta neden olur (2-5). Orta serebral arterin temporal dallarındaki oklüzyonlar da aynı alanda infarkta yol açabilir. Bununla birlikte arteryal infarktlarda insüler korteks tutulumu beklenir (2,4). Serebral venöz trombozun kontrastsiz bilgisayarlı tomografi (BT)'deki en önemli bulgusu, etkilenen parankimal alan komşuluğundaki oklüde vendeki hiperatenüe trombüstür ancak bu hiperatenüasyon SVT'li olguların yalnızca \%25'inde görülür.
Ayrıca atenüasyon artışı, dehidratasyonda, hematokrit düzeyinin arttığ1 durumlarda, subaraknoid ve subdural kanama sonrasında izlenebilir. Böyle olgularda ven atenüasyonu ile arter atenüasyonunu karșılaştırılarak fizyolojik ve trombotik atenüasyon artışları birbirinden ayırtedilebilir (1). Serebral 
venöz trombozu saptamada kontrastsiz MR inceleme, kontrastsiz BT incelemeden daha duyarlıdır. MR görüntülemede "akım kaybı"nın kaybı ve sinüsteki sinyal intensite değișikliği primer bulgulardir. Venöz trombozun T1 ve T2 AG'lerde sinyal intensitesi, trombüs formasyonunun ortaya çıkışı ile görüntüleme zamanı arasındaki intervale göre değişir. Sinyal intensitesindeki değişikliğin, trombüsteki hemoglobin yıkım ürünlerinin paramanyetik etkileri ile ilişkili olduğu düşünülür. Akut evredeki trombüs, T1 AG'de izointens, T2 AG'de hipointens izlenir ve normal akım durumunu taklit edebildiğinden tanısal hataya neden olabilir. Literatüre göre, sinüs trombozlu olguların \%10-30'unda görüntüleme akut evrede yapılmaktadır. Bu evrede doğru tanıya ulaşmak için kontrastlı MR venografi veya BT venografi çal1şılmalıdır. Subakut evrede trombüs

\section{KAYNAKLAR}

1. Dorndorf D, Wessl K, Kessler C, et al. Thrombosis of the right vein of Labbe: radiological and clinical findings. Neuroradiology 1993;35: 202-204.

2. Leach JL, Fortuna RB, Jones BV, GaskillShipley MF. Imaging of cerebral venous thrombosis: current techniques, spectrum of findings, and diagnostic pitfalls. Radiographics 2006; 26:Suppl 1:S19-41.
(6-15 günler), methemoglobin nedeniyle hem T1 AG'de hem T2 AG'de hiperintens izlenir. Subakut evre, trombüsün MR incelemede en kolay saptanabilen formasyon evresidir ve SVT'li olguların \%55'inde görüntüleme bu dönemde yapilır. Kronik trombüs (>15 gün), T1 AG'de izointens, T2 AG'de izo-hiperintens izlenir (1).

Kontrastlı incelemelerde SVT'nin iyi tanımlanmış bulgularından biri, kontrastlanan dural kollateral venöz kanallarla ve kavernöz boşluklarla çevrelenmiş trombüsü temsil "boş delta işareti” dir (1).

Serebral venöz trombozu saptamada en sik kullanilan venografik tetkikler kontrastsız MR venografi, kontrastlı MR venografi ve BT venografidir. İki boyutlu Time of flight (TOF) tekniği, yavaş akıma karşı mükemmel duyarlı-

3. Chakraborty S, terBrugge K, Farb R, Mikulis D. Case of the month \#140. Isolated cortical vein thrombosis of left vein of Labbe. Can Assoc Radiol J. 2008; 59: 271-274.

4. Jones BV. Cae 62: lobar hemorrhage from thrombosis of the vein of Labbe. Radiology 2003; 228:693-696. lığ1 ve 3 boyutlu TOF ile karşılaştırıldığında satürasyon etkisinden kaynaklanan sinyal kaybına azalmış duyarlılığı nedeniyle serebral venöz sistemi değerlendirmede siklıkla kullanilır. Ayrıca 2 boyutlu teknikler, görüntü elde edinim planına dik akımları saptamada en duyarlı olduklarından görüntü kazanımında tercih edilir (1).

Kortikal ven trombozu gelișmesi için risk faktörleri trombofili, hamilelik veya peripartum dönem, malign tümörler, oral kontraseptif kullanımı ve santral sinir sistemi enfeksiyonlarıdır (6).

Sonuç olarak, temporal lob lateral kesiminde, hemoraji veya ödem gibi parankimal değișiklikler Labbe ven trombozunun işaretçisi olabilir ve bu nedenle Labbe veninin dansite ve intensitesinin değerlendirilmesi, doğru tanının konması ve sonrasında uygun tedavinin uygulanması için gereklidir.

5. Kalpatthi R, Coley BD, Rusin JA, Blanchong CA. Neonatal temporal lobar hemorrhage secondary to thrombosis of the vein of Labbé. J Perinatol. 2005; 25: 605-607.

6. Gold M. Isolated Right Vein of Labbe Thrombosis. JAMA Neurol. 2016; 73: 120-121. 
